\title{
Utilizing Modular Labs in Human Anatomy and Physiology: Lessons Learned From a First Time Experience
}

Jennifer Zitzner

Loyola University Chicago, jzitzner@luc.edu

Follow this and additional works at: https://ecommons.luc.edu/biology_facpubs

Part of the Anatomy Commons, and the Biology Commons

\section{Recommended Citation}

Zitzner, Jennifer. Utilizing Modular Labs in Human Anatomy and Physiology: Lessons Learned From a First Time Experience. HAPS Educator, 21, 2: 137-142, 2017. Retrieved from Loyola eCommons, Biology: Faculty Publications and Other Works, http://dx.doi.org/10.21692/haps.2017.029

This Article is brought to you for free and open access by the Faculty Publications and Other Works by Department at Loyola eCommons. It has been accepted for inclusion in Biology: Faculty Publications and Other Works by an authorized administrator of Loyola eCommons. For more information, please contact ecommons@luc.edu.

\section{(c) (i) $\Theta$}

This work is licensed under a Creative Commons Attribution-Noncommercial-No Derivative Works 3.0 License. (C) Human Anatomy and Physiology Society 2017 


\title{
Utilizing Modular Labs in Human Anatomy and Physiology: Lessons Learned From a First Time Experience
}

\author{
Jennifer R. Zitzner, PhD \\ Loyola University Chicago, 1032 W. Sheridan Rd, Chicago, IL 60660 \\ jzitzner@luc.edu
}

\begin{abstract}
Anatomy and physiology laboratory experiences build upon concepts that are presented in the lecture part of the course. Our anatomy and physiology laboratory class meets weekly for approximately three hours and includes a compilation of activities that are to be completed during the laboratory period. While exercises are built off of topics presented in lecture and predominantly hands-on in nature, many students were not taking advantage of the self-directed learning experiences, especially those employing anatomical models. Some students were content to simply take photographs of models with their cell phones and complete only the graded portions of the laboratory assignment sheets. This behavior was not conducive to mastering the required anatomical details. To provide an enhanced learning environment, we reorganized the laboratory course and the lab manual into modules with the goal of creating a more focused laboratory experience. This article discusses the advantages and hurdles we experienced in the first year of a redesigned modular laboratory experience. doi: 10.21692/haps.2017.029
\end{abstract}

Key Words: laboratory modules, anatomy, physiology, undergraduate education

\section{Introduction}

Technology in the scientific laboratory allows instructors and students to experience anatomical and physiological concepts through realistic, hands-on demonstrations. However, student technology can also inhibit active learning by allowing students to take shortcuts in participation. For example, the use of cell phones or other camera devices in the laboratory allows students to quickly exit the laboratory without the more in-depth, hands-on learning experience envisioned and expected by the laboratory instructors. Aside from the distractions that student technologies can create, the photographic representations of anatomical structures, whether taken by the student, found on the Internet, or appearing in their textbooks, are flat, two-dimensional representations of three-dimensional structures. This poses a serious problem especially when identifying anatomical openings or overlying structures. Another challenge to our long-standing laboratory procedures has been that many students rush to complete the graded assignment sheets without completing and reviewing all of the activities that are included in the laboratory manual.

We presented our concerns at the Central Regional Human Anatomy and Physiology Society (HAPS) conference in November 2015 and found several instructors who struggled with the same challenges we faced in our laboratory. While many methods of improving laboratory instruction were discussed, ranging from prohibiting or limiting external electronic devices to moving to online systems for anatomical structures, we decided to explore presenting the material in modules, where the students would rotate through exercises of a particular concept or system. This would allow us to lead the students through the information in a more guided way and allow the students to focus their attention for a specific period of time on one area of content. We envisioned this would lead to an enhanced learning environment and an improved process of learning.

Inspired by our colleagues and the literature (Ganguly 2010, Miller SA et al. 2002), we set forth to design the modules in our laboratory manual. When thinking of a modular laboratory, we needed to define how we would create our modules. Modular laboratories have been used in several areas of science (Caprette et al. 2005,Chaplin 2003, Howard and Miskowski 2005) and medicine (Ferguson et al. 2013, Gahutu 2010, Zehr et al. 1996). Many modular designs were implemented in order to reinforce learning the scientific method and a single module might last for several weeks. We defined our modules as multiple related groups of information presented during a single laboratory session with the goal of creating a more focused and guided experience for our students. Specifically, the six laboratory tables in our lab space were designed to house either six different modules or two sets of three modules, through which students would rotate during the lab period.

In academic year 2016-2017, we reorganized the lab exercises used in previous years and into guided modules, which replaced the typical lists of anatomical structures and physiological concepts that should be mastered in the laboratory period. The goal of this project was to guide the students through anatomical and physiological concepts over a series of weeks implementing multiple exercises. We hoped that this method would improve the learning experience and possibly increase student retention of the material. Over the course of the academic year, we quantitatively compared laboratory practical examination 
scores to those of the previous year (non-modular format) and qualitatively analyzed student and instructor feedback in order to determine if modular laboratories led to increased understanding and student retention.

The intention of the laboratory change was to provide students with a focused subset of information before moving on to a related module. Although each week's modules explored similar topics or systems, different pedagogical methods were employed for each module. Pedagogical methods included the use of anatomical models, histological slides, anatomical dissection, computer simulations, and case studies. We anticipated that students would benefit from being directed to stay at each module for a specific period of time instead of being allowed to quickly progress through the modules at their own pace and completing only the graded work. Our expectation was that changing the methodology of the laboratory would serve to prepare students for further educational endeavors including upper-level courses and professional schools such as medical schools and advanced degree nursing schools.

\section{Student Population and Design of Modules}

At Loyola University Chicago, the human anatomy and physiology lab serves two populations of students. One student population consists of biology majors who typically take the course as undergraduate juniors and seniors. The second student population consists of allied health majors who are typically freshman nursing students or sophomore and junior exercise science majors. Students at both levels have approximately three hours of lecture and a threehour lab per week. The number of students enrolled in the anatomy and physiology labs during the two years compared in the study is shown in Table 1. The laboratory manual and materials are similar for both student populations but the expectation of learning and retention and the level of difficulty on the laboratory practical exams are greater in the biology majors course.

\begin{tabular}{|l|l|c|c|}
\hline & & Allied Health & Biology Majors \\
\hline $2015-2016$ & Fall & 201 & 239 \\
\hline & Spring & 180 & 157 \\
\hline $2016-2017$ & Fall & 230 & 215 \\
\hline & Spring & 205 & 152 \\
\hline
\end{tabular}

Table 1. Enrollment totals for the two years compared in the study. During the 2015-2016 year laboratory exercises were presented as a list for the students to work through. During the 2016-2017 year laboratory exercises were presented in modules when appropriate.

Eleven of the eighteen lab exercises presented through the year were amenable to a modular format. The material covered in modular form was the same as that which had been presented the previous year in non-modular form, with the additional material added, if necessary, to make the modules the appropriate length. When setting up the material to be covered in each module, consideration was given to the amount of material and the time needed to complete the exercise. After the instructor provided an introduction and brief description of the modules, students worked on each module in groups of four per table. During the fall semester lab sessions were divided into six modules and students moved between the modules at set twentyminute intervals. After the feedback from the fall semester, the length of time given for each module was increased to thirty minutes and the number of modules was limited to three per lab. In this case, two sets of the three modules were used. Time was allotted at the end of each laboratory for students to revisit any modules they had not completed or wanted to explore in more detail.

\section{Data Collection and Feedback Methods}

Quantitative data was used to analyze scores on laboratory practical exams and qualitative assessments, using anonymous surveys, were made of student and instructor feedback. Laboratory practical exam scores for students using the new modular guided laboratory manual were compared to the scores from the previous year when the exercises were non-modular. It is important to note there is some variation in the part time faculty who staff some of the lab sections. Average scores from each laboratory practical exam were gathered and compared for the two academic years covered by the study.

Qualitative data was collected and recorded in survey form. Students and instructors were asked several questions regarding how their perceived or observed understanding of lab concepts changed with the use of the guided modular exercises. Surveys assessing efficiency and retention of information acquired during the laboratory modules were given at the end of the fall semester so that we could improve on the modular arrangement of the laboratory for the spring semester. All data from surveys were anonymous to protect both student and instructor identities. Participation in the surveys was voluntary with no "extra-credit" points given for completing the survey.

This project was approved by the Internal Review Board of Loyola University Chicago's Office of Research Services and was considered to be under exempt status. Students were made aware of the change in laboratory methodology from the beginning of the semester. The following statement was inserted into the course syllabus:

"At the end of the course, a voluntary survey will be given evaluating the effectiveness of learning and retention using the laboratory modules. No results from these surveys will be viewed until all final grades are given and results will not affect in any way the outcome of your overall grade." 
A verbal description of the change in methodology was also given on the first day of class.

\section{Quantitative analysis of laboratory practical scores}

The laboratory exercises and practical exams were scheduled as in previous years. Three laboratory sessions were followed by a laboratory practical exam. Therefore, each semester provided three quantitative measures. No student identifying information was recorded. The data was divided into two groups (allied health majors and biology majors) to make comparable measurements. The quantitative scores for each practical are summarized in Figure 1.
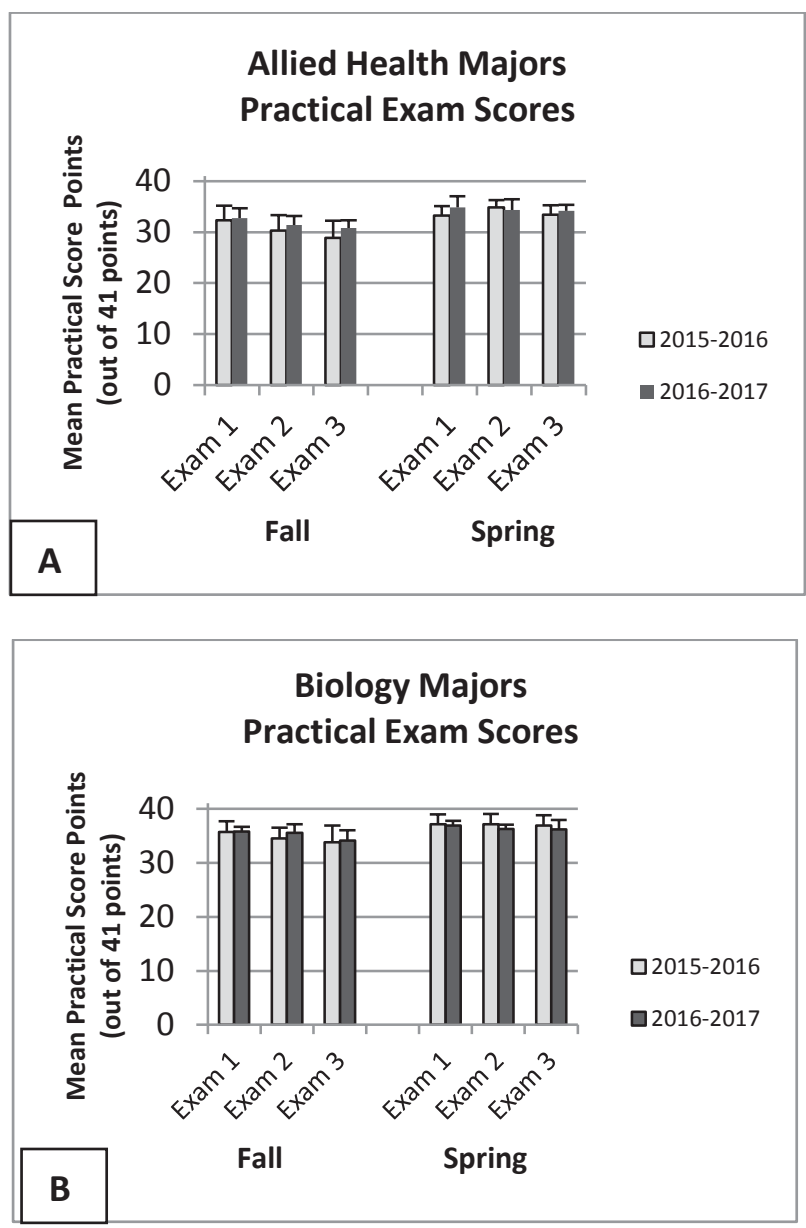

Figure 1. Average laboratory practical exam scores with modular laboratory exercises (2016-2017; black bars) compared to the previous year with a non-modular laboratory manual (2015-2016; grey bars). A) Average practical exam scores for allied health majors. B) Average practical exam scores for biology majors. The bars for both graphs represent the standard deviation.
As shown by the comparison of the two consecutive years with different laboratory content delivery methods, there was no measurable difference in laboratory practical exam scores between the two years. Feedback from instructors and students was also analyzed.

\section{Student Feedback}

Student surveys consisted of two components: statements that were rated from strongly agree to strongly disagree and two free response questions. The rated survey statements are presented in Table 2 . Since surveys were voluntary, not all students completed surveys and the number of student responses is noted in the table. Overall, student responses from the two subsets of students were very similar and highlighted that the modular laboratory format was helpful in focusing student attention on the material as well as keeping students on track. Both groups found that the modular laboratory helped students work together as a team and provided an effective learning environment.

While the responses to statements showed a positive experience with the modular laboratory format, the free response questions showed areas where improvements could be made. Two free response questions were asked:

1) In your own words, did you find learning the laboratory material in modules rather than a list of activities effective?

2) Please offer any suggestions to improve the laboratory modules. (What worked and what did not work?)

Student comments to the free response questions varied however, two major themes emerged. The first theme was that the modular format provided a guided experience in the laboratory. While the students did not have the experience of previous years to compare (no control group was employed in this analysis), the majority of students found the delivery of the material to be effective. However, the overwhelming criticism was that the modules were either too short or too long for the prescribed amount of time before rotating to the next module. For modules that were considered too short because of lack of activities or working speed of the group, the students had to wait for time to rotate. Students felt rushed if they had not completed the exercise material in the allotted time. Time was allocated at the end of the laboratory for students to return to any module they had not completed but most students did not utilize this opportunity. Students also commented that they preferred to work at their own pace or to work individually rather than in a group. Neither of these choices conforms to the delivery of modular content we designed. 


\begin{tabular}{|c|c|c|c|c|c|c|c|c|c|c|}
\hline \multirow{3}{*}{\begin{tabular}{|l|}
\multicolumn{1}{|c}{ Survey Question } \\
Strongly Disagree (1) -> \\
Strongly Agree (5)
\end{tabular}} & \multicolumn{5}{|c|}{ Allied Health Majors ( $n=213$ ) } & \multicolumn{5}{|c|}{ Biology Majors $(n=184)$} \\
\hline & 1 & 2 & 3 & 4 & 5 & 1 & 2 & 3 & 4 & 5 \\
\hline & & & & & & & & & & \\
\hline $\begin{array}{l}\text { The modular laboratory } \\
\text { sessions helped keep me on } \\
\text { track and focused on the } \\
\text { laboratory material }\end{array}$ & $3 \%$ & $7 \%$ & $26 \%$ & $44 \%$ & $20 \%$ & $4 \%$ & $7 \%$ & $14 \%$ & $37 \%$ & $38 \%$ \\
\hline $\begin{array}{l}\text { The modular laboratory } \\
\text { sessions helped my retention of } \\
\text { the material by allowing time to } \\
\text { study and quiz my fellow } \\
\text { classmates. }\end{array}$ & $6 \%$ & $14 \%$ & $30 \%$ & $34 \%$ & $16 \%$ & $6 \%$ & $15 \%$ & $21 \%$ & $28 \%$ & $30 \%$ \\
\hline $\begin{array}{l}\text { The laboratory modules were } \\
\text { not an efficient way to deliver } \\
\text { the laboratory material. }\end{array}$ & $27 \%$ & $39 \%$ & $17 \%$ & $12 \%$ & $6 \%$ & $27 \%$ & $35 \%$ & $10 \%$ & $15 \%$ & $13 \%$ \\
\hline $\begin{array}{l}\text { The laboratory modules } \\
\text { allowed me to focus on smaller } \\
\text { regions of the anatomy of the } \\
\text { body. }\end{array}$ & $1 \%$ & $5 \%$ & $20 \%$ & $48 \%$ & $27 \%$ & $2 \%$ & $5 \%$ & $15 \%$ & $42 \%$ & $37 \%$ \\
\hline $\begin{array}{l}\text { The guided modules for } \\
\text { learning the regional anatomy } \\
\text { (muscles and bones) allowed } \\
\text { me to organize and structure } \\
\text { the material into more } \\
\text { manageable units. } \\
\end{array}$ & $2 \%$ & $3 \%$ & $24 \%$ & $39 \%$ & $31 \%$ & $2 \%$ & $5 \%$ & $18 \%$ & $36 \%$ & $39 \%$ \\
\hline $\begin{array}{l}\text { The laboratory modules helped } \\
\text { develop my skills in working as } \\
\text { a team. }\end{array}$ & $2 \%$ & $11 \%$ & $15 \%$ & $46 \%$ & $25 \%$ & $4 \%$ & $11 \%$ & $24 \%$ & $32 \%$ & $28 \%$ \\
\hline \begin{tabular}{|l|} 
The laboratory modules \\
provided an effective learning \\
environment
\end{tabular} & $3 \%$ & $6 \%$ & $21 \%$ & $44 \%$ & $26 \%$ & $3 \%$ & $8 \%$ & $23 \%$ & $34 \%$ & $32 \%$ \\
\hline
\end{tabular}

Table 2. Voluntary student survey responses evaluating the modular laboratory format. Values are percentages relative to the total number of participants.

\section{Instructor Feedback}

Instructors were asked to provide feedback on the modular laboratory format. All surveys were voluntary and no instructor identification information was recorded on the surveys. The statements and responses from the instructor survey are listed in Table 3.

Responses indicated that the modular laboratory format was generally a positive experience for the instructor. Instructors noted that students were not always satisfied with the format, which corresponds to the comments listed above. Overall, the instructors generally agreed that the laboratory modules were an effective and efficient way to deliver the material each week.
Instructors were also given two free response questions to give additional comments on their experience in the laboratory. The questions were:

1) In your own words, did you find student learning of the laboratory material in modules rather than as a list of activities effective?

2) Please offer any suggestions to improve the laboratory modules (What worked and what did not work?)

Instructors commented that the modules helped divide the material into manageable amounts that kept the students focused on the task and on track during the laboratory. Instructors indicated that the most significant pitfall was when the students finished a module early or perceived that they did not have enough time to finish a module before moving on to the next. This corresponds to the information gathered from student surveys.

\section{Discussion}

The anatomy and physiology laboratory is designed to complement the content that is provided in the lecture portion of the course. While our laboratory instructors were satisfied with the activities performed in the laboratory, we were discouraged by the shortcuts and perceived learning that was occurring as a result of student technology and lack of focus on the activities provided. Therefore, we set forth to change the method of delivery of our laboratory exercises and activities to allow students to focus on smaller portions of the material at one time and to require students to move through each exercise on a prescribed time schedule.

\begin{tabular}{|l|c|c|c|c|c|}
\hline \multirow{2}{*}{ Instructor Survey Responses (n=10) } & \multicolumn{4}{|c|}{ Strongly Disagree (1) -> Strongly agree (5) } \\
\cline { 2 - 6 } & $\mathbf{1}$ & $\mathbf{2}$ & $\mathbf{3}$ & $\mathbf{4}$ & $\mathbf{5}$ \\
\hline $\begin{array}{l}\text { The modular laboratory sessions helped } \\
\text { keep students on track and focused on the } \\
\text { laboratory material }\end{array}$ & $0 \%$ & $0 \%$ & $30 \%$ & $40 \%$ & $30 \%$ \\
\hline $\begin{array}{l}\text { The laboratory modules provided an } \\
\text { effective learning environment }\end{array}$ & $0 \%$ & $0 \%$ & $10 \%$ & $60 \%$ & $30 \%$ \\
\hline $\begin{array}{l}\text { The laboratory modules provided } \\
\text { increased student learning and retention } \\
\text { of material }\end{array}$ & $0 \%$ & $10 \%$ & $40 \%$ & $50 \%$ & $0 \%$ \\
\hline $\begin{array}{l}\text { Students enjoyed working in laboratory } \\
\text { modules }\end{array}$ & $0 \%$ & $10 \%$ & $40 \%$ & $50 \%$ & $0 \%$ \\
\hline $\begin{array}{l}\text { As an instructor, the laboratory modules } \\
\text { helped deliver the laboratory more } \\
\text { effectively/efficiently }\end{array}$ & $0 \%$ & $0 \%$ & $20 \%$ & $40 \%$ & $40 \%$ \\
\hline
\end{tabular}

Table 3. Voluntary instructor survey responses evaluating the modular laboratory format. Values are percentages relative to the total number of participants. 
After quantitatively examining the practical exam scores between the years using a standard manual versus a modular format, we saw no measurable difference in scores. While we did expect that scores would increase with the modular format, the goal of the change in laboratory format was to help students learn the material and to avoid perceptions that the information was best understood by simply taking pictures of models or by completing only the pages of the manual that would be graded.

Student and instructor responses indicated that the goal of organizing the laboratory exercises in a more manageable and focused way through modules did prove to be effective. However, the most frequently listed comment for improvement, from both instructors and students, was the length of time spent at a module and amount of content at each module. To address this, when setting up the laboratory modules, it is important to think about the diversity in the student population, especially in terms of educational background. Students with a more extensive background in science may work at a faster pace, as some of the concepts may already be understood. However, if students do not have a solid science background, as is the case for many of our allied health students, more time may be needed to fully grasp the concepts presented.

Although our biggest challenges during the first year were inconsistencies in content quantity and time allotted per module, the modules can be modified for the following years. For example, comments from students after their first semester indicated that more time was needed at some the modules, and the logistics of moving between six modules was more disruptive than we had imagined. Therefore, we altered the second semester to contain duplicate sets of three, longer modules. The potential problem with this change is the availability of resources in the lab (specimens, anatomical models, histological slides, etc.)

We also found that student perceptions of the laboratory experience seemed to vary according to the laboratory section. This led us to believe that some lab instructors may have influenced student perceptions. If there are multiple sections of the laboratory course, it is important that all instructors agree on how the modules should be presented and a discussion of best practices for helping the students maximize the experience at each module is vital.

\section{Conclusion}

The goal of our project was to assess the effectiveness of using modular laboratory exercises in the anatomy and physiology laboratory at Loyola University Chicago. We aimed to assess whether changes to our laboratory methods improve the effectiveness of learning in our laboratory. While the delivery of the material as modules changed between the two years analyzed, the content remained very similar; therefore, we aimed to assess only the delivery and teaching methods in this study.

While the overall feedback was positive, there were some hurdles that any laboratory may experience when trying a new delivery model. Although the quantitative practical exam scores did not differ, both students and instructors felt the laboratory allowed students to focus on smaller portions of material and stay on track throughout the laboratory session. However, careful planning needs to take into consideration the amount of time and content per module. Assessing the needs and background of student population and explaining the purpose of the modular setup will help identify the expectations for the laboratory experience.

\section{About the Author}

Jennifer R. Zitzner is an advanced lecturer in the Department of Biology at Loyola University Chicago. She teaches undergraduate human anatomy and physiology for biology majors and allied health majors and is interested in incorporating pedagogical techniques for lecture and laboratory settings that improve engaged learning and retention for students.

\section{Acknowledgements}

I would like to acknowledge and thank Drs. Patrick Duffie and Robert Morgan for their contributions to the modular lab manual and the collection of quantitative data and editing of this manuscript. Their experience, advice, and help in debating the best pedagogy for the laboratory sections shaped the lab manual each semester. I would also like to thank all of the laboratory instructors who gave feedback each week and helped to make the modular laboratory project a positive experience.

\section{Literature cited}

Caprette DR, Armstrong S, Beason KB (2005) Modular Laboratory Courses. Biochemistry and Molecular Biology Education. 33, 351-355. doi: 10.1002/ bmb.2005.49403305351

Chaplin SB (2003) Guided Development of Independent Inquiry in an Anatomy/Physiology Laboratory. Advances in Physiology Education. 27, 230-240. doi: 10.1152/ advan.00002.2003

Ferguson PC, Kraemer W, Nousiainen M, Safir O, Sonnadara R, Alman B, Reznick R (2013) Three-Year Experience with an Innovative, Modular Competency-Based Curriculum for Orthopaedic Training. Journal of Bone and Joint Surgery. 95, e166(1-6). doi: 10.2106/JBJS.M.00314

Gahutu JB (2010) Physiology teaching and learning experience in a new modular curriculm at the National University of Rwanda. Advances in Physiology Education. 34, 11-14. doi: 10.1152/advan.00093.2009 
Ganguly PK (2010) Teaching and Learning of Anatomy in the $21^{\text {st }}$ Century: Direction and the Strategies. The Open Medical Education Journal. 3, 5-10.

Howard DR and Miskowski JA (2005) Using a Module-based Laboratory To Incorporate Inquiry into a Large Cell Biology Course. Cell Biology Education. 4, 249-260. doi: 10.1187/cbe.04-09-0052

Miller SA, Perrotti W, Silverthorn DU, Dalley AF, Rarey KE (2002) From College to Clinic: Reasoning Over Memorization Is Key for Understanding Anatomy. The Anatomical Record. 269, 69-80. doi:10.1002/ar.10071

Zehr CL, Butler RG, Richardson RJ (1996) Students' Use of Anatomy Modules in Problem-based Medical Education at McMaster University. Academic Medicine. 71, 1015-1017. 